\title{
A TEORIA E A PRÁTICA EM GEOLOGIA E O ETERNO RETORNO
}

\author{
CELSO D.R. CARNEIRO****;,CARLOS A.L.S.CUNHA** e GINALDO A.C.CAMPANHA*
}

\begin{abstract}
THEORY AND PRACTICE IN GEOLOGY AND THE ETERNAL RECURRENCE. Several years ago an ancient paper regarding the relationship between theory and practice originally writen by a chinese politician and educator was re-written with emphasis to Geology to support teaching activities. Since that time it has been applied to post-graduate activities. The adapted text is presented and discussed. It stresses the knowledge levels developed by man in studying nature as well as the importance of field work to geology work. It is emphasized that field practices are needed not only to allow students to improve their understanding of the external dynamics of the Earth's crust but also to allow them to rediscover the theoretical paths used to reconstruct the Earth's geologic evplution. The entwinning between theory and practice, as examplified by natural dynamics, follows the cyclic evolution of scientific knowledge, along a continuous and permanent recurrence.
\end{abstract}

Keywords: Theory, practice, scientific method, Geology, teaching, learning, field geology, praxis.

\begin{abstract}
RESUMO 0 tema da teoria e prática em Geologia foi abordado em texto de suporte para atividades didáticas de pós-graduação lato-sensu há alguns anos atrás e, desde então, tem sido instrumento de reflexão, em sala de aula, sobre a importância do campo para as atividades geológicas. Resultante da adaptação de uma obra não-geológica de autor chinês, o texto focaliza os sucessivos níveis cognitivos do contato do Homem com a Natureza. Notáveis questões epistemológicas despontam desse entendimento, com desdobramentos para atividades de laboratório e outras práticas didáticas: o campo proporciona contínua interação entre teoria-prática, indispensável para um adequado processo de ensino-aprendizagem em Geociências. O entrelaçamento da teoria e prática, a exemplo da dinâmica natural, acompanha o desenvolvimento cíclico do conhecimento, segundo um contínuo e permanente
\end{abstract} retomo entre ambos.

Palavras-chave: Teoria, prática, método científico, Geologia, ensino, aprendizagem, geologia de campo, praxis.

Nenhum problema geológico pode ou deve ser tratado como amadorismo puro; ele será sempre delimitado com um certo objetivo prático Yu. A. Kozygin (1970 apud Cruza, Romanovsky 1975)

INTRODUÇÃO Há consenso, para os estudiosos das Ciências da Terra, de que teoria e prática são absolutamente indissociáveis. Embora seja fácil traduzir tal conceito em exemplos, aparecem muitas sutilezas ao procurarmos descrevê-lo por meio de explanação teórica conveniente.

Em 1979, um grupo de geólogos com experiência didática e preocupados com questões educacionais foi convidado a ministrar curso de especialização, numa universidade federal, para professores de Geologia no nível superior. $\mathrm{Na}$ oportunidade, o entendimento mais adequado das relações da teoria com a prática constituiu um desafio para a equipe docente, da qual os Autores faziam parte ${ }^{1}$.

$\mathrm{Na}$ preparação do módulo específico sobre ensino de campo, foram escolhidos, em publicações especializadas, artigos sobre a necessidade de viagens de campo no ensinoaprendizagem de geologia; foi relativamente simples preparar uma excursão para que o corpo discente (os "professoresalunos") discutissem formas de empregar as excursões como recurso de ensino. A organização do curso estava equacionada, mas não havíamos resolvido a questão de tratar das relações teoria-prática: como é feita a ponte entre as observações de campo e os conceitos prévios dos estudantes? Quais as formas apropriadas para estimular sua participação, sem gerar bloqueios a priori, que impeçam aproveitamento efetivo da atividade de campo? De que modo teoria e prática se interrelacionam?

$\mathrm{O}$ aprofundamento filosófico do problema exigiria, no entender da equipe docente, textos de suporte, que fossem além dos fundamentos do tema: necessitávamos de material que se aproximasse da vivência do público-alvo. Para distinguir os conceitos de "teoria" e "prática", entre si, não bastaria caracterizar a ambos por meio de definições. Era preciso enfatizar ligações e a possível interdependência dessas idéias e concepções.

A solução encontrada foi recorrer a um texto de cunho geral, elaborado por um político e educador chinês "nãogeólogo", destinado a finalidades diferentes daquelas que o curso estabelecia. Optou-se por uma adaptação livre, adicionando-se exemplos ligados ao dia-a-dia do geólogo e mantendo-se a maior fidelidade possível à obra original, com base na versão em Português de que dispúnhamos.

$\mathrm{O}$ texto foi empregado em cursos subsequentes, revelando certo interesse didático. Este ensaio se propõe a apresentá-lo e a discutir aspectos importantes dessa temática em educação. $\mathrm{O}$ fato de o aluno ser visto hoje como construtor de seu próprio conhecimento (Santos \& Praia 1992) obriganos a considerar os atos didáticos sob novos ângulos e sob o ponto de vista dos objetivos principais do ensino-aprendizagem. Várias pesquisas sobre o campo como recurso didático em geologia fundamentam-se nessa análise. Trata-se, pois, de reflexão necessária e oportuna.

O PROBLEMA DO ENSINO DE CAMPO O módulo de campo, no curso de 1979, foi orientado para aprofundar aspectos relevantes do contato do profissional e do estudante de geologia com o ambiente natural. A dinâmica das atividades deveria chamar a atenção para: 1. os diferentes objetivos que os trabalhos de campo permitem atingir; 2 . as particula-

\footnotetext{
${ }^{(1)}$ Participaram também os seguintes docentes: C. Paschoale, LA. Amaral, M.G. Tessler e O.B.M. Negrão.

* Divisão de Geologia, Instituto de Pesquisas Tecnológicas do Estado de São Paulo, Caixa Postal 7141, CEP 01064-970, São Paulo, SP, Brasil ** Área de Educação Aplicada às Geociências, Instituto de Geociências, Universidade de Campinas, Caixa Postal 6152, CEP 13081-970, Campinas, SP, Brasil
} 
ridades de intenso envolvimento dos estudantes durante os trabalhos de campo; e 3. o fato de que, no campo, ocorre um processo criativo relevante. Nesse processo, os estudantes relacionam-se com uma nova realidade; obtêm dados e informações; adquirem conceitos; iniciam a formulação de novas idéias sobre a natureza.

A lacuna na abordagem dos temas centrais do ensino de Geologia de Campo pode ser visualizada na ementa específica para cursos de graduação em Geologia, conforme o "Currículo Mínimo" aprovado no II Simpósio Nacional "O ensino de Geologia no Brasil" (SBG 1983, p. 25).

Matéria que trata da metodologia fundamental para produção da informação geológica. Representa o aprendizado de métodos e técnicas de COLETA E FORMALIZAÇÃO PARA REPRESENTAÇÃO DA INFOR$M A C ̧ \tilde{A O}$ GEOLÓGICA, significando COLETA o conjunto de operações realizadas no campo para obtenção da informação e FORMALIZAÇÃO PARA REPRESENTAÇÃO o conjunto de procedimentos para a produção de documentos (...) (Destaques do original).

A "Geologia de Campo" não precisa necessariamente estar contida em uma única disciplina, podendo ser dispersa em mais de uma, ou disseminada no conjunto delas (SBG 1983, p. 28). Sua carga horária mínima, no curso de graduação, deve ser de 800 horas (SBG 1983).

Os cursos de Geologia, no País, contemplam o ensino de Geologia de Campo, geralmente com ênfase nas atividades de mapeamento geológico. Do mesmo modo, excursões e viagens de campo são também incluídas no programa das mais de 700 disciplinas introdutórias de conteúdo geológico, ministradas em grande parte das instituições de ensino superior do país. Esse amplo leque de professores emprega livremente sua experiência prévia para conceituar "coleta e formalização da informação geológica".

ADAPTAÇÃO No trabalho adaptado, por razões que adiante são referidas, adotou-se um pseudónimo: o primeiro nome era apelido de um autor (GACC) e o segundo, uma sigla formada pelas iniciais do outro (CDRC).

"Uma Visão do Problema da Teoria e Prática em Geologia" Alexey Cedrec

$A$ afirmação de que "o conhecimento geológico não pode prescindir da prática" tem sido correntemente invocada como argumento para demonstrar que, em geologia, com caráter mais acentuado que em outras ciências, a prática e a teoria não podem ser dicotomizadas. Existiria realmente tal caráter particular da geologia no contexto dos ramos do conhecimento humano? Seria possivel demonstrar o inverso, ou seja, que o conhecimento geológico pode ser desligado da prática? Tais preocupações devem ser analisadas sob o prisma do processo de desenvolvimento do conhecimento humano em geral, e do conhecimento geológico em particular. Uma análise assim conduzida oferece, num primeiro instante, elementos para definir a natureza do conhecimento geológico e o sentido que assume a prática no seu processo de desenvolvimento.

No início do processo da atividade prática, os homens visualizam apenas o aspecto exterior dos diferentes fenômenos encontrados ao longo deste processo; eles vêem aspectos isolados dos fenômenos e a ligação externa dos fenômenos isolados. Tomemos, por exemplo, um grupo de geólogos que pela primeira vez investiga uma região desconhecida: sua atividade, a princípio, restringe-se em observar as feições isoladas, os tipos de materiais presentes, as configurações e os fenômenos particulares existentes; tudo isso são os aspectos exteriores dos materiais, feições isoladas dos fenômenos da natureza, das quais se reconheceram as ligações externas. Esse grau do processo do conhecimento chama-se grau da percepção sensível, isto é, o grau das sensações e das representações. Os geólogos de nosso exemplo tiveram através de seus órgãos dos sentidos algumas sensações determinadas; na sua consciência surgiu toda uma série de representações e estabeleceu-se um laço aproximativo, exterior, entre as representações: tal é o primeiro grau do conhecimento. Nesse grau, os homens não podem elaborar conceitos profundos nem proceder a conclusões lógicas ${ }^{2}$.

A continuação da atividade prática implica a múltipla repetição de observações que suscitam sensações e representações no homem. É então que se produz na consciência humana uma mutação súbita (um salto) no processo do conhecimento: o aparecimento dos conceitos. O conceito não reflete mais os aspectos exteriores dos fenômenos, as feições isoladas dos materiais, a sua ligação externa; ele capta a essência dos fenômenos, os fenômenos no seu conjunto, a ligação interna entre eles. Entre o conceito e a sensação, a diferença não é somente quantitativa, ela é também qualitativa. $O$ desenvolvimento que intervém ulteriormente nesta direção, o emprego dos métodos de juízo, de dedução, podem desembocar em conclusões lógicas. Quando se diz, correntemente: "Deixe-me refletir", isso significa que o homem opera intelectualmente usando conceitos, a fim de fazer juízos e proceder a deduções. Esse é o segundo grau do conhecimento. Os geólogos do exemplo, após coletarem e examinarem dados variados, poderão afirmar: "Essa região foi anteriormente submetida a intenso vulcanismo ". A conclusão baseia-se na percepção inicial e na comparação entre os elementos reunidos sobre situações atualmente observadas em outros locais. No processo geral do conhecimento de qualquer fenômeno pelos homens, esse grau dos conceitos, dos juízos e das deduções aparece como um grau ainda mais importante, o grau do conhecimento racional. A verdadeira tarefa do conhecimento consiste em elevar-se da sensação ao pensamento até a elucidação progressiva dos fenômenos que existem objetivamente, suas leis, a ligação interna dos diferentes processos, isto é, consiste em atingir o conhecimento lógico.

Nós repetimos: o conhecimento lógico difere do conhecimento sensível na medida em que o conhecimento sensivel abraça aspectos isolados dos fenômenos, os seus aspectos exteriores, a ligação externa dos fenômenos, enquanto o conhecimento lógico, dando um enorme passo à frente, abarca os fenômenos por inteiro, a sua essência e a ligação interna, eleva-se até o ponto de evidenciar as contradições internas do mundo objetivo (e suas leis) e, por isso mesmo, pode chegar a dominar o desenvolvimento desse mundo na sua integridade, com as suas ligações gerais internas.

No movimento do conhecimento sensivel ao conhecimento lógico, esses dois graus constituem os graus de um processo único do conhecimento. O conhecimento sensível e o conhecimento racional diferem pelo seu caráter, mas não estão separados um do outro; estão unidos na base prática. A nossa prática testemunha que os fenômenos de que temos percepção sensivel não podem ser imediatamente compreendidos por nós, e só os fenômenos compreendidos podem ser sentidos de maneira mais profunda. A sensação não pode resolver mais do que o problema dos aspectos exteriores dos fenômenos; o problema da essência não pode ser resolvido senão pelo pensamento teórico. A solução destes problemas não pode ser separada, de modo algum, da prática. Todo aquele que quiser conhecer um fenômeno não

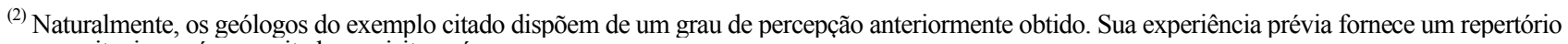
conceituai, que é aproveitado ao visitar a área.
} 
poderá consegui-lo sem se por em contato com esse fenômeno, isto é, sem viver (entregar-se à prática) em seu próprio seio

O conhecimento é uma questão de ciência, não admite a menor desonestidade ou presunção. O que se requer é precisamente o contrário - honestidade e modéstia. Se se deseja adquirir conhecimentos, há que tomar parte na prática que transforma a realidade. Se se quer conhecer $o$ gosto de uma pêra, há que transformá-la, prová-la. Se se quer conhecer a estrutura e as propriedades do átomo, há que entregar-se a experiencias fisicas e químicas, modificar o estado do átomo. Todos os conhecimentos autênticos resultam da experiência direta. No entanto, o homem não pode ter experiência direta de tudo, razão pela qual a maior parte de nossos conhecimentos (individuais) é, na realidade, obtida indiretamente, pela experiencia acumulada de outros homens. Por isso, os conhecimentos do homem se compõem de duas panes: os dados da experiência direta e os dados da experiência indireta. Contudo, o que é para um individuo experiência indireta, permanece para outros como experiência direta. Segue-se daí que, falando dos conhecimentos no seu conjunto, pode-se dizer que nenhum conhecimento autêntico pode ser desligado da experiencia direta. A fonte de todo conhecimento são as sensações recebidas do mundo exterior objetivo, pelos órgãos dos sentidos dos homens, ou seja, pela prática. Os chineses têm um velho provérbio que diz: "Se não se penetra no covil do tigre não se lhe podem apanhar as crias ". Este provérbio é verdadeiro para a prática humana e, na mesma medida, para a teoria do conhecimento. O conhecimento desligado da prática é inconcebivel.

Em consequência, o primeiro passo no processo do conhecimento é o primeiro contato com os fenômenos do mundo objetivo: o grau das sensações. O segundo é a síntese dos dados fornecidos pelas sensações, a sua ordenação e elaboração: o grau dos conceitos, dos juízos e das deduções. Somente em presença de um grande número de dados fornecidos pelas sensações (não dados fragmentários, incompletos) e apenas no caso de estas corresponderem à realidade (quer dizer, no caso de não serem o resultado de um erro dos sentidos), torna-se possível, com base nesses dados, elaborar conceitos correios e formular uma teoria adequada.

Para refletir plenamente um fenômeno na sua totalidade, para refletir a sua essência e suas leis internas, é preciso criar um sistema de conceitos e teorias. Isto depois de se ter submetido os múltiplos dados da percepção sensível a um processo de eliminar o que é falso e conservar o verdadeiro, em passar de um aspecto dos fenômenos a outro, do externo ao interno. Essa elaboração não torna os conhecimentos menos ricos, menos seguros. Pelo contrário, tudo o que, após ter surgido no processo de conhecimento na base prática, foi submetido a uma elaboração científica e organizou-se em teoria, reflete o mundo objetivo de uma maneira mais profunda, mais justa, mais completa.

Se, no entanto, é atingida uma teoria adequada, contentando-se em dela fazer um simples tema de conversação, esta teoria, por mais bela que seja, não poderá ter qualquer significação. A função ativa do conhecimento não se restringe ao salto do conhecimento sensivel ao conhecimento racional. Um vez adquirido o conhecimento teórico, devese dirigi-lo para a prática da transformação do mundo e para a prática da experimentação científica. Tal é o processo de verificação e desenvolvimento de uma teoria, a continuação de todo o processo de conhecimento. A questão de saber se uma proposta teórica corresponde à verdade objetiva não é inteiramente resolvida no movimento do conhecimento sensível ao conhecimento racional. Para resolver completamente essa questão é necessário, a partir do conhecimento racional, regressar à prática. Aplicar a teoria na prática e verificar se ela pode ser confirmada. A conclusão de que a nossa hipotética região tivesse sofrido fenômenos vulcânicos no passado pode ser testada pelo grupo de geólogos, por intermédio de novas pesquisas de campo, procurando reconhecer estruturas e sequências efusivas ou localizar possíveis chaminés vulcânicas.

Muitas teorias das ciências da natureza foram reconhecidas como verdadeiras, não só pelo fato de terem sido elaboradas por pessoas que se devotam a essas ciências, mas também por terem encontrado confirmação na prática científica ulterior. A história do conhecimento humano mostra que a verdade de muitas teorias científicas era incompleta, mas em consequência da verificação na prática, essa insuficiência foi eliminada. Muitas teorias eram incorretas mas, em consequência da verificação na prática, suas incorreções foram eliminadas.

É aqui que se conclui o movimento do conhecimento? Pode ser que sim, pode ser que não. Se na aplicação ulterior de idéias, teorias, planos eprojetos, numa prática relacionada ao mesmo processo objetivo estudado, alcança-se o resultado esperado, ou seja, se se consegue pelo menos em linhas gerais transformar em realidade as idéias, teorias, planos e projetos, o conhecimento desse processo objetivo pode ser considerado terminado. Contudo, de um modo geral, é extremamente raro que as teorias elaboradas pelos homens se realizem sem sofrer a mínima alteração. Isto porque as pessoas que estudam e trabalham sobre a realidade encontramse geralmente condicionadas por múltiplas limitações. Elas encontram-se limitadas não somente pelas condições técnicas e científicas, mas pelo próprio grau de desenvolvimento do processo que estão estudando e pelo grau em que este se manifesta. No caso de nosso exemplo, o fato de que os fenômenos vulcânicos não ocorrem atualmente na área pode limitar o estudo pela destruição parcial de registros, superposição de outros fenômenos mais recentes etc.

Estas limitações significam que existem casos em que as idéias, teorias, planos e projetos, tal como tinham sido originariamente elaborados, não correspondem empane ou no todo à realidade, de onde resultam parcial ou totalmente incorretos. Em muitos casos, só depois de repetidos fracassos consegue-se eliminar as incorreções, obter a correspondência com as leis do processo objetivo estudado, o que quer dizer, chegar - na prática - aos resultados esperados.

Todavia, considerando-se os processos concretos no seu desenvolvimento, o movimento do conhecimento humano não termina aí. Conforme os processos modificam-se e desenvolvem-se, torna-se necessário que o conhecimento humano também se modifique em função dos novos problemas.

Pela prática, chega-se ao conhecimento e, igualmente pela prática, este é confirmado e desenvolvido. Passa-se ativamente do conhecimento sensivel ao conhecimento racional, o qual guia-nos novamente à prática. A prática, o conhecimento, e novamente a prática e o conhecimento, nessa forma, na sua repetição cíclica, constituem uma progressẫo infinita.

A preparação desse texto foi gratificante; isso pode ser melhor avaliado se o leitor se dispuser a saborear a obra original (MAO 1937). Aquela época, sob regime militar, era imprópria para divulgar textos dessa natureza, principalmente em curso realizado em uma instituição universi-

(3) "A expressão 'o bacharel, sem atravessar o umbral de sua porta, pode conhecer tudo o que se passa na terra' era uma frase vazia dos tempos antigos em que a técnica não estava ainda desenvolvida, e se na nossa época de técnica desenvolvida isso aparece realizável, apenas os indivíduos ligados à prática do 'que se passa na terra' podem possuir conhecimentos autênticos, adquiridos graças à sua experiência pessoal; esses indivíduos, na sua prática, adquirem 'conhecimentos' que, graças à escrita e à técnica, podem ser transmitidos ao bacharel, dando-lhe a possibilidade de conhecer, indiretamente, 'tudo o que se passa na terra', (trecho colhido do original, que não fazia parte da versão editada em 1979). 
tária federal, apoiado por recursos de origem igualmente federal. São essas as razões do pseudónimo escolhido.

Idéias situadas originalmente no contexto das relações humanas, sociais e políticas, graças às transposições efetuadas, ganharam afinidade com o trabalho em geologia. Parecem extrapoláveis para a natureza, apesar de fatores como o "tempo", mudanças políticas mundiais recentes (o original foi escrito há mais de meio século) e eventuais questões de ordem político-ideológica, que podem polarizar o debate, além de fugir do escopo desta nota.

Conceitos Os termos "praxis" e "prática", utilizados em Português, diferem entre si, porque o primeiro tem aceitação apenas filosófica - "e mesmo assim, nem sempre" (Vázquez 1968). Emprega-se praxis para designar, num sentido amplo, em Filosofia, a atividade humana que produz objetos, a atividade material do homem social ou, ainda, a atividade social transformadora (Vázquez 1968), procurando-se desse modo afastar o significado meramente utilitário de prática para o senso comum ("homem prático", "resultado prático" etc.).

Entretanto, a origem do termo grego praxis significa uma "ação que tem fim em si mesma". Isso se contrapõe à "ação que cria ou produz um objeto alheio ao agente ou sua atividade". Para manter o sentido rigoroso das palavras, "poiésis" seria a designação correia desta última ação. Contudo, em nosso idioma, poiésis corresponde a "poesia", "poético" ou "poeta", ou seja, introduz novas conotações que causam, possivelmente, mais controvérsia.

Prático seria o ato ou objeto que produz utilidade material, vantagem ou benefício. Para a consciência comum, aquilo que é prático é identificado como algo produtivo. $\mathrm{O}$ homem comum se auto-considera verdadeiramente prático; ele faz uso de tudo que o cerca, entendendo que as coisas existem para satisfazer necessidades imediatas do cotidiano. A vida prático-utilitária, que decorre das aspirações "práticas" do homem comum, coloca-se em clara oposição à prática revolucionária, pois afasta este último da atividade realmente transformadora (Vázquez 1968, p. 13). A utilidade direta e imediata gera um mundo onde a consciência do homem fica castrada ou esvaziada.

Teorias científicas são abordagens sistemáticas, em um dado campo de estudo, derivadas de um conjunto de proposições gerais.

Atividade significa ação (Fig. 1): corresponde ao ato ou conjunto de atos que modifica $(\mathrm{m})$ algo exterior (matériaprima etc.) e que é (ou são) imanente(s) ao agente. A idéia de atividade opõe-se à de passividade; a ação deve ser efetiva e total, não apenas possível, nem desarticulada. Agente é quem atua, ou age, não o que simplesmente tem condições de atuar ou agir.

A atividade propriamente humana implica, adicionalmente, a intervenção da consciência: os atos, dirigidos a um objeto no sentido de transformá-lo, se iniciam a partir de um resultado ideal, ou finalidade e terminam com um resultado final ou produto efetivo.

$\mathrm{Na}$ figura 2, partindo-se de um estado inicial efetivo (indicado pelo algarismo 1), a intervenção da consciência promove, na mente humana, a idealização de uma nova situação (2) que irá dirigir os atos subsequentes (3). O passo imediato é a criação de um anseio por um resultado ideal, que gera uma finalidade (4). A atividade (5) corresponde à efetivação dessas fases, não importando se elas tenham sido instantâneas ou detidamente planejadas. Desemboca-se, pois, numa situação final concreta (6). Esta última não necessariamente coincide com a situação final desejada.

Assim, os atos:

"não só são determinados casualmente por um estado anterior que se verificou efetivamente - determinação do passado pelo presente -, como também por algo que ainda não tem existência efetiva e que, não obstante, determina e regula os diferentes atos antes de culminar num resultado real; ou seja, a determinação não vem do passado, mas sim do futuro" (Vázquez 1968, p. 187).

$\mathrm{O}$ homem comum se auto-define como o ser prático que

\section{Atividade ou ação \\ Definição genérica}

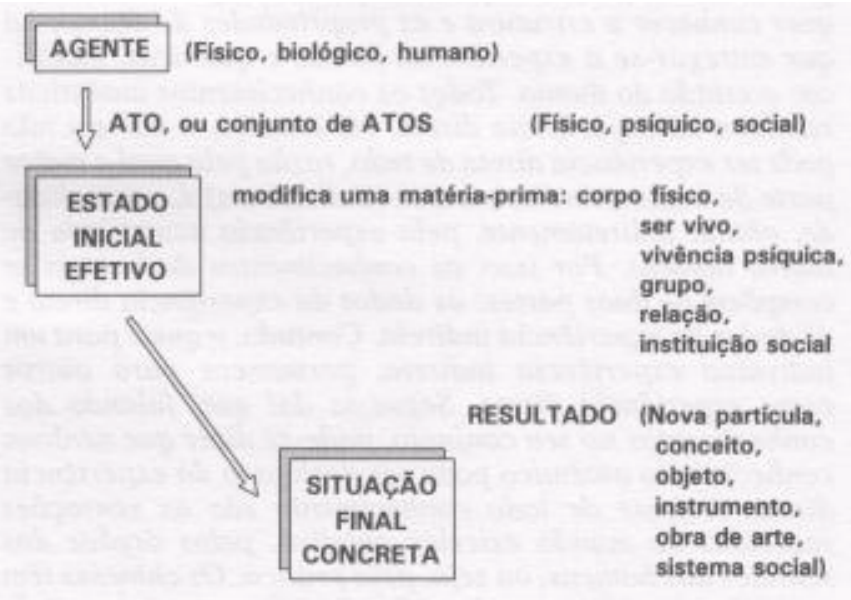

Figura 1 - Definição genérica de atividade ou ação, inspirada em Vázquez (1968)

Figure 1 - Generic definition of activity or action, inspired from Vázquez's ideas (1968)

\section{Atividade especificamente humana \\ A intervençăıo da consciência}

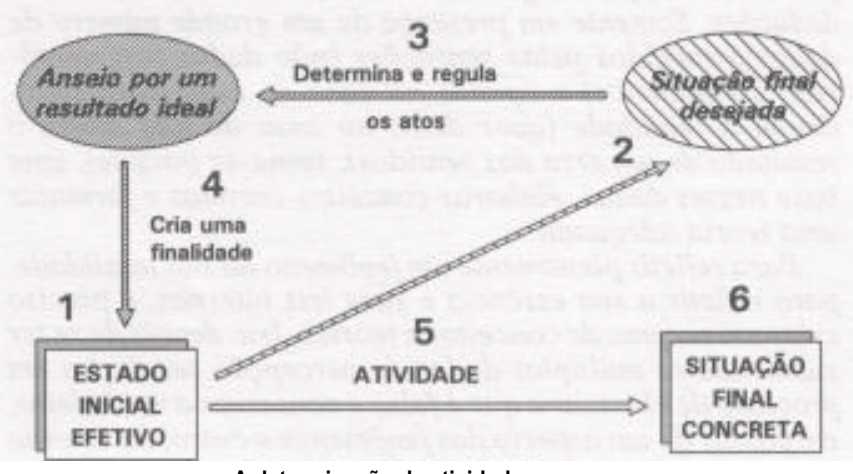

A determinação da atividade

não vem do passado, mas do futuro

Figura 2-A intervenção da consciência, determinante da atividade especificamente humana. Inspirada em Vázquez (1968)

Figure 2 - The influence of conscience on a specific human activity. Inspired from Vázquez (1968)

não precisa de teorias: os problemas se solucionariam na própria prática ou na sua revivificação, a experiência. Assim estabelecida, a prática distingue-se da atividade teórica (que seria improdutiva por excelência), mas este conceito é parcial: considera somente a atividade mecânica ou instintiva, apesar de exigir certa intervenção da consciência (Vázquez 1968, p. 15). Não atinge, portanto, reflexão teórica consistente.

A valorização do homem como ser social, ativo e transformador implica abandonar a consciência comum da praxis em busca de uma transformação. Pelas restrições acima, 
acreditamos ser importante, aqui, a distinção de "praxis" e "prática", segundo a conceituação de Vázquez (1968). O adjetivo "prática" restringe-se à qualidade de algo utilitário (pessoa prática etc.)- O substantivo prática é mais abrangente, porque descreve a ação humana transformadora e produtiva. As referências de Mao (1937) à prática coadunam-se com esta concepção. Nesse ponto de vista, praxis e prática são conceitos congruentes e intrínsecos à história humana.

A idéia de que o homem se faz a si mesmo e se eleva como ser humano justamente pela sua atividade prática, com seu trabalho, transformando o mundo material - idéia que só surgirá na consciência filosófica moderna - era, em geral, alheia ao pensamento grego. Para este, o homem se aprimora exatamente pelo caminho inverso: pela isenção de qualquer atividade prática material e, portanto, separando a teoria, a contemplação, da prática. (Vázquez 1968, p. 17)

Praxis e prática, entendidos como sinônimos na qualificação acima, descrevem atos e ações cuja sucessão faz parte da história do Homem. Esta, por seu turno, consiste no processo de formação e auto-criação do próprio homem.

A PRAXIS DA GEOLOGIA As atividades realizadas no campo pelos estudiosos e profissionais de ciências naturais fazem parte de um processo transformador por excelência, que envolve tanto a aquisição de conhecimento como, possivelmente, a posterior modificação do meio ambiente ou aproveitamento de seus recursos. Essas idéias são adiante discutidas. Interessa agora enfatizar uma nítida correspondência com o que se definiu como atividade propriamente humana, ou seja, reconhecer que está implícita a idéia de finalidade. No campo não ocorre uma atividade qualquer; a "prática da geologia" envolve as conotações de transformação e de intencionalidade. Para avaliar esses aspectos, é preciso analisar duas particularidades da geologia: a relevância do campo e das informações ali obtidas.

A importância do campo em geologia Os trabalhos de campo compõem o principal meio de que os geólogos dispõem para efetivar sua prática. As amostras, informações primárias e dados específicos de propriedades, características e distribuição de rochas, relevo, vegetação e solos, ali recolhidos, possibilitam o reconhecimento de uma dada região ou país.

E permanente a transição do registro dos fenômenos do mundo objetivo até a síntese desses dados na forma de conceitos, teorias e leis, tal como formulado por Mão (1937). Os dados da experiência indireta (aquela obtida por outros estudiosos num dado tema ou sobre uma dada situação real) exercem influência decisiva.

As relações entre teoria e prática situam-se, para o geólogo, nas transposições entre o registro e a síntese e no modo como se efetiva a incorporação dos dados indiretos. As reconstruções são também indiretas, pois o estudo de fenômenos do passado requer raciocínio indutivo e analogias, além de depender das pistas obtidas no presente (Carneiro et al 1993).

Os dados da experiência indireta são fundamentalmente obtidos a partir da literatura ou da transmissão verbal, mas é preciso reconhecer que estes foram gerados com base em dados de campo de determinadas regiões do globo. E comum, no caso do Brasil, os geólogos terem acesso a bibliografia e conhecimentos produzidos em países de clima temperado. A transposição não pode ser imediata, porque, nos ambientes tropicais, a profunda alteração intempérica irá exigir métodos adequados para entendimento dos registros gravados nas rochas e outros materiais. Feições numerosas são descaracterizadas, dissimuladas ou encobertas por fenômenos que não ocorrem com a mesma intensidade nos climas temperados dos países desenvolvidos. Por essa razão, é insatisfatório importar, sem reservas, técnicas, conceitos e soluções de outros países. É necessário desenvolver uma ciência e uma técnica adequada às condições nacionais, que permitam decifrar o mascaramento das rochas e depósitos minerais devido ao intemperismo. As diferenças, em natureza e qualidade, da pesquisa do subsolo em regiões tropicais, em relação àquela realizada no primeiro mundo, determinam que se recorra ao campo, continuamente, para observar os fenômenos, as rochas e os demais materiais naturais tal como se encontram.

A necessidade da informação geológica Outro aspecto pecular da praxis da geologia é o da informação geológica, cuja demanda é crescente, mesmo nos países desenvolvidos, devido ao crescimento populacional e desenvolvimento económico. $\mathrm{O}$ desafio ambiental abriu novos campos de atuação para a Geologia (Oliveira et al 1991), pois o estudo de processos da dinâmica interna e externa da Terra se insere no "sistema ambiental mais amplo, incluindo os meios biológico e sócio-econômico" (Oliveira et al 1991).

A informação correia e detalhada lança as bases do planejamento urbano e controle ambiental (COGEMIN 1991) por órgãos de governo, sejam eles federais, estaduais ou municipais. Modernamente, as atividades tendem a se desdobrar em três ramos principais, buscando harmonizar o aproveitamento de recursos naturais com a preservação do meio ambiente (Carneiro 1992):

- ações basicamente exploratórias em Geologia partem do conceito de recursos ("as substâncias minerais não constituem recursos, elas se tornam recursos", Spooner 1981). Em outros termos, a água, os minérios, os materiais empregados na construção civil, os combustíveis fósseis, os fluidos de origem geotermal e os demais fatores que permitem obtenção de energia (hidroeletricidade, energia solar, das marés, eólica etc.) são explotados pelo Homem com maior ou menor intensidade nas diferentes regiões geográficas, dependendo de suas necessidades;

- as ações preventivas constituem outra forma de aplicação do conhecimento acumulado: a geração de novos métodos e técnicas para equacionar a atividade humana sobre o meio ambiente busca minimizar os impactos ambientais futuros;

- ações corretivas consistem, igualmente, na aplicação do conhecimento e geração de novos mecanismos: (1) de avaliação de situações de desequilíbrio significativo entre produtos da ação humana e a dinâmica da natureza e (2) de implementação de medidas capazes de restaurar o equilíbrio ou minimizar os efeitos negativos identificados.

Tais ações fazem parte da praxis da geologia. Por outro lado, sua condução adequada depende da disponibilidade e, até mesmo, da qualidade da informação geológica existente. O planejamento exige base geológica adequada; entretanto, o generalizado desconhecimento dos beneficios da informação confiável do solo e subsolo (beneficios práticos imediatos) parece ter levado os líderes, os políticos e a própria sociedade brasileira a "redescobrir", sucessivas vezes, essas exigências. Raramente é reconhecido o papel dos segmentos de infra-estrutura; tampouco há apoio compatível com sua importância estratégica. A informação interessa diretamente às empresas de mineração, empresas petrolíferas ou produtoras de água subterrânea, assim como, de resto, a toda a atividade industrial: na manutenção de suas redes de suprimento de matérias-primas; na escolha de locais mais adequados para suas instalações; no planejamento de seus sistemas e redes de transporte; no planejamento da disposição de seus resíduos.

A própria construção civil e a ocupação urbana e rural dependem de dados confiáveis sobre evolucão crustal, estabilidade sísmica regional e velocidades de processos da dinâmica natural das encostas. 
As atividades de campo são a fonte primordial dessa informação que interessa simultaneamente a vários setores. $\mathrm{O}$ conselho "conhece-te a ti mesmo", aplicado às nações, estados, regiões e territórios, é instrumento de valorização e aproveitamento de recursos naturais, com a finalidade de promover a melhoria das condições sócio-econômicas de sua população, sem prejudicar a qualidade de vida ou do meio ambiente.

Para melhorar o alcance da praxis da geologia, não há desmerecimento algum se o geólogo profissional e o educador em Geociências se esforçarem na divulgação, à sociedade, dos benefícios e vantagens práticas imediatas de seus trabalhos.

DISCUSSÃO Na profícua experiência de 1979, o corpo discente discerniu a profundidade e a força dos argumentos do texto. A organização fluente das idéias é favorecida pela linguagem, simples e direta; são, afinal, qualidades desejáveis em qualquer síntese. Conceitos aparentemente óbvios ganharam nova roupagem durante as discussões, extrapolando, de longe, o objetivo inicial. A inegável necessidade de trabalhos de campo no ensino mostra ser pertinente o estudo da relação teoria $x$ prática.

A figura 3 discrimina a ciclicidade das transposições entre teoria e prática como uma interdependência de ambos, à semelhança de engrenagens que se tocam e interpenetram. Esse modelo limitado simboliza, por exemplo, de que forma acontece, no plano teórico, a partir de uma visita inicial de campo, uma reflexão sobre a atividade, um aprofundamento teórico e sucessivos retornos ao campo. Entretanto, a figura é demasiadamente estática: não representa o aprimoramento crescente da capacidade observacional e investigativa dos participantes do processo, ou daqueles que indiretamente conhecem seus efeitos.

Outro modelo que parece adequado para situar essa questão é a "hipótese da lagarta" (Fig. 4), extraída de interessante artigo sobre as peculiaridades da formação do geólogo (De Waal 1988). O autor admite que "uma ciência não pode se desenvolver adequadamente sem o apoio de uma profissão" e, para ilustrar a idéia, faz analogia sobre as relações entre uma determinada ciência e a profissão correspondente (no sentido estrito de "comércio" do conhecimento científico na indústria). $\mathrm{O}$ modelo propõe que, num certo momento, os avanços da ciência "puxam" a profissão e, logo a seguir, a profissão realiza avanços importantes que "empurram" a ciência para a frente. Vimos que, em geologia, transposições semelhantes, entre a teoria e a prática, ocorrem com enorme frequência. $\mathrm{O}$ modelo tem ainda a vantagem de mostrar que ambos os fatores estão indissoluvelmente unidos.

A excursão de um dia, integrante daquele módulo, aprofundou a discussão sobre as dificuldades e peculiaridades reais da formação profissional em Geologia. Foram levantados vários aspectos do método científico, desde os princípios de investigação até questões de ensino-aprendizagem. $\mathrm{O}$ grupo ficou convencido de que podem existir diferentes graus de dependência de conceitos prévios dos alunos para a realização de excursões. A complexidade e extrema variedade das situações encontradas no campo proporcionam ambiente favorável para novos insights teóricos. A história pessoal dos participantes, muitas vezes, fica marcada por esse tipo de acontecimentos.

A barreira da introdução dos alunos no campo não se resume à existência, ou não, de conhecimentos prévios suficientes, mas é importante considerar a forma como são explorados, durante as excursões, o universo das sensações e as primeiras etapas da transmissão de novos conceitos. Ao se aproveitar a vivência anterior dos estudantes, deixa-se em aberto, até mesmo, a possibilidade de viagens ao campo em situações de baixa informação prévia de geologia pelos alunos. Carneiro \& Campanha (1979) e Compiani \& Carnei-

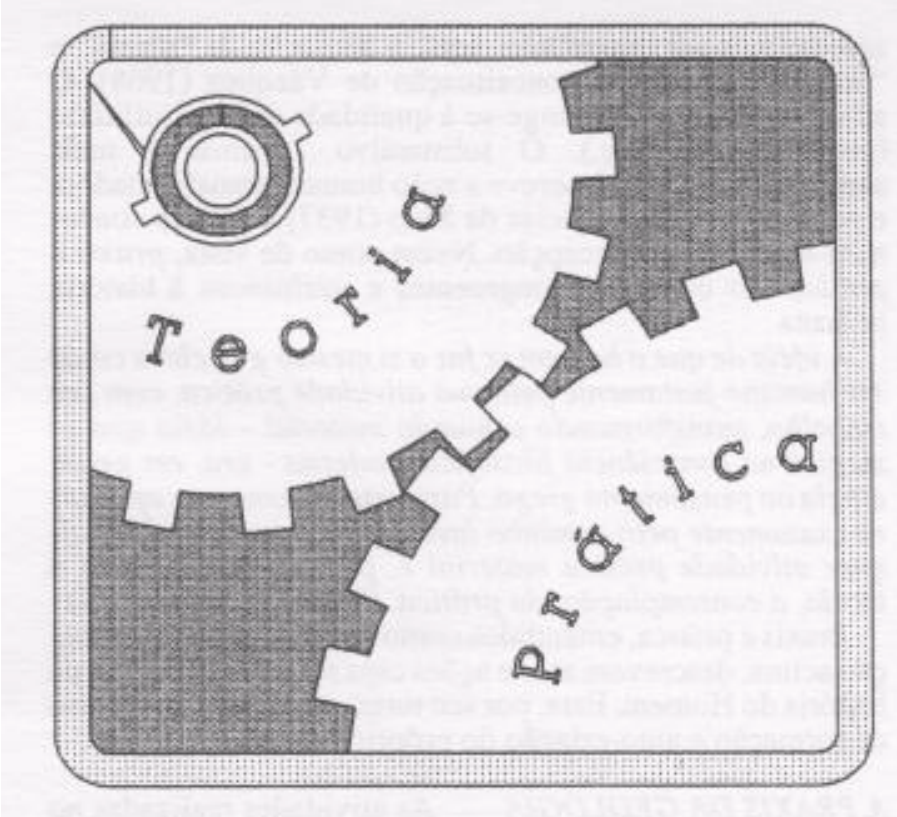

Figura 3 -A relação entre a teoria e a prática, representada em um corte, no qual há duas engrenagens interligadas. Uma visita inicial de campo desencadeia uma reflexão sobre a prática, um aprofundamento teórico, novos contatos com o campo e assim por diante

Figure 3 - The relationship between theory and practice here represented as a plane with two linked gears. An initial visit to the field unleashes a reflection on the practice, succeeded by a theoretical approach, new contacts with the field and so on

ro (1993), dentre outros, discutem essa alternativa: as chamadas excursões motivadoras.

$\mathrm{Na}$ vivência dos presentes Autores sobre as relações entre teoria e prática em Geologia repetiram-se sucessivas vezes as etapas de ênfase ora na teoria, ora na prática. Poderíamos afirmar que, no início, havíamos atingido o grau da percepção sensível, sem ter clareza dos significados que estávamos reconhecendo. $\mathrm{O}$ estudo teórico do tema, a prática e novos retornos à teoria, proporcionados pela literatura e reflexão, contribuíram para melhorar o entendimento. No campo, é permanente a interação dos papéis da teoria e da prática; essa relação, intrínseca à geologia (como ciência e como profissão) leva-nos a admitir que as hipóteses das engrenagens e da lagarta sejam satisfatórias.

$\mathrm{Na}$ avaliação que hoje fazemos daquele curso, prejudicada pelos filtros que o tempo inevitavelmente estabelece, podemos perceber que houve pouco avanço no estudo das características geológicas da distante região visitada. Sob este aspecto, não havíamos superado (no sentido de ir além de) a etapa do conhecimento racional, muito embora não fosse objetivo dos participantes realizar, a posteriori, sínteses acerca da geologia da área. Esse fraco desenvolvimento dos estudos regionais (talvez mais próximo do domínio da percepção sensível) decorrera da priorização dada aos aspectos teóricos e da preocupação em transmitir aos alunos nossa avaliação de que os trabalhos de campo são fundamentais.

A repetição cíclica referida por Mao (1937) corresponde a planos sucessivos nos quais os estudiosos das ciências da natureza assumem responsabilidades cada vez mais abrangentes na apropriação de conhecimentos e na formulação de teorias que vão sendo testadas e, pela prática, reavaliadas, modificadas ou substituídas por novas formulações. Em uma primeira oportunidade o campo estimula e exercita a percepção sensível; a seguir, reelaboram-se os dados; em novo contato com a natureza, outros aspectos são levantados e assim os trabalhos prosseguem, movimentando as "engrenagens". 


\section{O EFEITO DA LAGARTA}
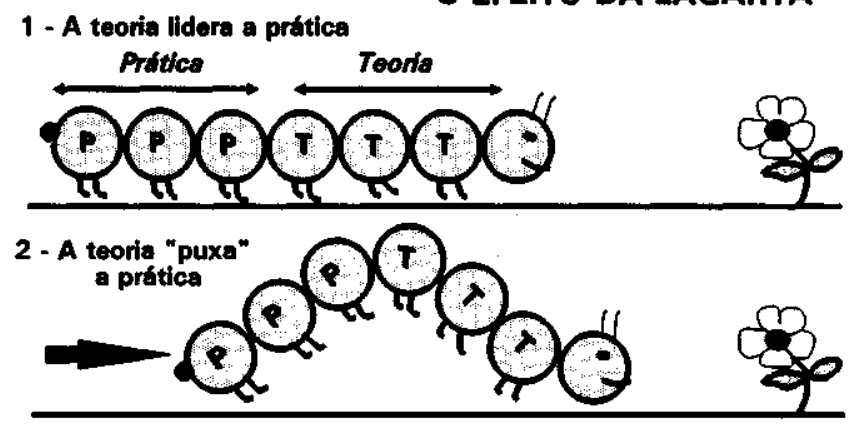

3 - A pratica "empurra"

a teoria

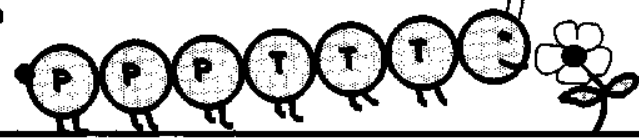

Figura 4 -A relação entre a teoria e a prática, representada por meio da "hipótese da lagarta". Num momento inicial qualquer, a teoria lidera a prática; no momento seguinte, a teoria "puxa" a prática, mas é por ela impulsionada logo a seguir, quando a prática "empurra" a teoria Figure 4 - The relationship between theory and practice, represented by the "caterpillar hypotheses". During a given first step, theory leads practice; in a following moment, it "pulls" practice, but it suffers a new impulse, when practice "pushes" theory

O texto apresentado é instrumento de trabalho que reflete ampla gama de preocupações. Evidencia a imperiosa necessidade de contato do profissional que lida com a natureza com seu específico laboratório - o campo - e mostra-nos um quadro elegante de permanente recorrência, talvez no sentido do "eterno retorno" a que se refere Nietzsche:

"A hipótese de um mundo criado não deve afligir-nos nem por um instante.(...) Este mundo, (...) uma monstruosidade de força, sem início, sem fim, (...) ao mesmo tempo um e múltiplo, aqui acumulando-se e ao mesmo tempo ali minguando, um mar de forças tempestuando e ondulando em si próprias, eternamente mudando, eternamente recorrentes, com descomunais anos de retorno, com uma vazante e enchente de suas configurações..." (Nietzsche 1881-1888, p. 396-397).

Para Nietzsche, a imagem da eternidade é o círculo. A eterna recorrência dos mesmos eventos a intervalos de tempo gigantescos seria, para aquele filósofo, a mais científica das hipóteses. Se não aceitarmos as explicações bíblicas sobre a origem do mundo, não haveria um começo para o passado, nem um estado final estável, a ser um dia atingido. Concepção semelhante pode ser encontrada entre os pioneiros da Geologia. Hutton assim descrevera os fenômenos naturais:

"Se a sucessão dos mundos é estabelecida no sistema da natureza, é em vão procurar por algo na origem última da Terra. Entretanto, o resultado da nossa presente investigação indica que não há vestígio de um início nem perspectiva de um fim". (Hutton 1788, p. 304 apud Gonçalves 1992)

A única alternativa para Nietzsche é a de que as configurações se repitam a si mesmas depois de enormes intervalos de tempo. São especulações que podem ser exemplificadas no trecho:

"Aquele imperador tinha constantemente presente a transitoriedade de todas as coisas, para não lhes dar demasiada importância e permanecer tranquilo no meio delas. A mim parece, ao inverso, que tudo é de demasiado valor para poder ser tão fugaz: procuro uma eternidade para cada coisa: seria permitido despejar os mais preciosos bálsamos e vinhos no mar? - meu consolo é que tudo o que foi é eterno: - o mar os traz de volta." (Nietzsche, 1881-1888, p. 396) (grifos do original).

A duração da vida humana constitui mero flash na sequência histórica dos fenômenos naturais. Alguns autores propõem a definição de um novo período na história do planeta - o tecnogênico ou quintenário - iniciado há aproximadamente 10.000 anos, a partir dos primeiros registros geológicos do homem como agente modificador da paisagem (Ter-Stepanian 1988 apud Inda \& Costa 1992). Em sentido oposto, acham-se as opiniões sobre a descoberta do "tempo profundo" (deep time), conceito que introduziu, segundo Gould (1991), enorme limitação temporal à importância do ser humano. A geologia impôs a todos nós a constatação da vastidão "quase incompreensível de tempo, com a habitação humana restrita a um milimicrossegundo do extremo final" < da escala de tempo geológico $>$ (Gould 1991). Isso obriga-nos a aceitar que existe, naquela forma de enxergar a dinâmica dos fenômenos mais recentes (quaternários), um certo orgulho ingênuo e uma supervalorização da condição humana.

O modelo cíclico e as interrelações de escala (Inda \& Costa 1992) dos fenômenos naturais do planeta são, porém, muito úteis para outra analogia sobre as relações teoria $x$ prática. A exemplo da dinâmica natural, o desenvolvimento do conhecimento é cíclico e obedece a um contínuo retorno entre a prática e a teoria. Numa visão evolucionista moderna, a noção de ciclicidade dos fenômenos tem sido revista (Carneiro et al. 1993), admitindo-se retornos a situações equivalentes, com resultados semelhantes, mas não idênticos. A figura da espiral helicoidal é razoável para representar as transposições entre teoria e prática, uma vez que, a exemplo de uma espiral no tempo, as engrenagens movimentam-se sucessivas vezes sem retornar às situações anteriores. A forma geométrica da espiral refere-se essencialmente à configuração espacial, não à velocidade com que as interações ocorrem. A frase de Heráclito "não se atravessa duas vezes o mesmo rio" sintetiza essa idéia: na segunda travessia, o viajante não é mais o mesmo, nem se trata do mesmo rio.

A necessidade de transferir os conhecimentos e experiências de maneira correta entre os cientistas, e mesmo entre os membros de uma dada comunidade, constitui outro problema relevante para análise, centrado na comunicação interpessoal. No presente estágio de discussão, consideramos prematuro estender esse tema, pois ele abre, novamente, um amplo campo de investigação metodológica.

CONSIDERAÇÕES FINAIS O campo é a espinha dorsal da atividade do geólogo, talvez mais acentuadamente que para outros estudiosos do meio natural. É no campo que ele coleta seu material básico de trabalho: os dados e informações. Sua importância é, de fato, inestimável e sua riqueza, inesgotável.

Em geologia, a teoria não pode ser desvinculada da prática; conșiste, obrigatoriamente, numa reflexão sobre esta última. É válido comparar a ciclicidade da dinâmica terrestre com o ciclo de geração do conhecimento, principalmente se considerarmos os percalços que a realidade e os conflitos humanos impõem a este último. Duas analogias podem ser formuladas: tanto a hipótese das engrenagens como a da "lagarta" colocam as interrelações segundo um mesmo plano. Se aceitarmos, porém, que existe um progressivo estado de mudança no desenvolvimento dos conceitos e teorias, a figura da espiral helicoidal (não ilustrada neste trabalho) parece mais adequada. A transposição permanente entre teoria e prática possibilita gerar novos conceitos, numa situação de eterno retorno, em que a espiral do conhecimento avança cada vez mais e melhor, dependendo da efetividade dessa relação. 
Não obstante, o ciclo só se completará se for eficiente também a transmissão desses conhecimentos e experiências de maneira adequada, de uma pessoa para as outras, de um cientista a outros, ou de um professor para seus alunos. Note-se que haveríamos de salientar o problema (fundamental) da comunicação humana: o aspecto referido por Mão (1937) de que "... <a maior parte de> nossos conhecimentos (individuais) é, na realidade, obtida indiretamente, através da experiência acumulada de outros homens". Neste breve espaço, parece difícil avançar em mais esse estimulante tema, apenas para não perder de vista o escopo principal do trabalho.

\section{REFERÊNCIAS BIBLIOGRÁFICAS}

CARNEIRO, C.D.R. 1992. Perspectivas do profissional de geociências num cenário de retomada do crescimento econômico brasileiro. In: CONGR. BRAS. GEOL., 37. São Paulo, 1992. Publicação Especial.. São Paulo, SBG. (apud oral, mesa redonda "O Profissional e a Ciência").

CARNEIRO, C.D.R.; BRITO-NEVES, B.B.; AMARAL, LA.; BISTRICHI, C.A. 1993.0 Atualismo como princípio metodológico em Tectônica. Bol. Geoc. PETROBRÁS, (no prelo)

CARNEIRO, C.D.R. \& CAMPANHA, G.A.C. 1979. O ensino de campo em geologia. In: CURSO DE ESPECIALIZACÃO EM ENSINO SUPERIOR DE GEOCIÊNCIAS, 1. Belém, 1979. Apostila... Belém, UBPA. (Mimeogr., Módulo).

COMPIANI, M. \& CARNEIRO, C.D.R. 1992. Os papéis didáticos das excursões geológicas. Rev. de la Ensenanza de las Ciências de la Tíerra, 1(2):90-98.

CONSELHO ESTADUAL DE GEOLOGIA E RECURSOS MINERAIS. 1991. Diretrízes para uma Politica Estadual de Geologia e Recursos Minerais. São Paulo, COGEMIN. 88 p. (Inédito).

GOULD, S.J. 1991. Seta do Tempo, Ciclo do Tempo: Mito e Metáfora na Descoberta do Tempo Geológico. São Paulo, Cia. das Letras. 221 p.

GRUZA, V.V. \& ROMANOVSKIY, S.I. 1975. The principle of actualism and logic in understanding the geologic past. Int. Geol. Rev., 17(2): 167-174.

INDA, H.A.V. \& COSTA, L.A.M. 1992. Fundamentos da Geologia Pós-Moderna. Rio de Janeiro, CPRM. 8 p. (Série Sinopses, DGH/S/A004-92)

MAO, TSE TUNG 1937. Sobre a prática. In: SAMPAIO, C.A. Filosofia de Mao Tse Tung. Belém, Boitempo. p. 12-29. (Cole- ção Teoria Hoje, textos extraídos de Mao Tse Tung Selected Writings. Pequim 1975).

NIETZSCHE, F. 1881-1888. Sobre o niilismo e o eterno retorno. In: Obras Incompletas. 2 ed. São Paulo, Abril. 1978. p. 377-397 (Os pensadores, seleção de textos de G. Lebrun, trad. R.R. Torres P).

OLIVEIRA, A.M.S.; FORNASARI FILHO, N.; AUGUSTO FILHO, O. PRANDINI, F.L. 1991. Geologia de Engenharia e meio ambiente. In: SIMP. GEOL. SUDESTE, 2. São Paulo, 1991. Atas... São Paulo, SBG. p. 293-296.

PASCHOALE, C. 1984. Alice no país da Geologia e o que ela encontrou lá In: CONGR. BRAS. GEOL., 33. Rio de Janeiro, 1984. Anais... Rio de Janeiro, SBG. v. 5, p. 242-249.

SANTOS, E.M. \& PRAIA, J.F. 1992. Percurso de Mudança naDidática das Ciências. Sua Fundamentação Epistemológica. Aveiro, Univ. Aveiro. p. 7-34. (Ensino das Ciências e Formacão de Professores 1).

SOCIEDADE BRASILEIRA DE GEOLOGIA 1983. Currículo Mínimo. In: SIMP. NAC. ENSINO DE GEOLOGIA NO BRASIL, 2. Salvador, SBG. Documento Final... Salvador, SBG. 73 p. (CONGR. BRAS. GEOL., 32).

SPOONER, D. 1981. Mining and Regional Development. Oxford, Oxford Univ. Press. 60 p. (Theory and Practice in Geography).

VÁZQUEZ, A.S. 1968. Filosofia da Praxis. São Paulo, Paz e Terra. 243 p. (Série Rumos da Cultura Moderna 2).

MANUSCRITO A757

Recebido em 7 de abril de 1993

Revisão do autor em 16 de setembro de 1993

Revisão aceita em 27 de setembro de 1993 